RUNNING HEAD: EMOTIONAL INTELLIGENCE, COMMUNICATION AND

SOCIAL COHESION

Emotional intelligence, communication competence and student perceptions of team social cohesion

\author{
ASHLEA C. TROTH \\ Griffith Business School \\ Griffith University \\ Brisbane, Queensland, Australia 4111 \\ Tel: (+61) 737355241 \\ Fax: (+61) 737353887 \\ Email: A.Troth@griffith.edu.au \\ PETER J. JORDAN \\ Griffith Business School \\ Griffith University \\ Brisbane, Queensland, Australia 4111 \\ Tel: (+61) 737353717 \\ Fax: (+61) 737353887 \\ Email:Peter.Jordan@griffith.edu.au \\ SANDRA A. LAWRENCE \\ Centre for Work, Organisation \& Wellbeing \\ Griffith Business School \\ Griffith University \\ Brisbane, Queensland, Australia 4111 \\ Tel: +61 (07) 37357132 \\ Fax: +61 (07) 37354298 \\ Email:S.Lawrence@griffith.edu.au
}

Manuscript Submitted To The Journal of Psychoeducational Assessment, Special Edition On

Emotional Intelligence. 


\title{
Emotional intelligence, communication competence and student perceptions of team social cohesion
}

\begin{abstract}
Students generally report poor experiences of group work in university settings. This study examines whether individual student perceptions of team social cohesion are determined by their level of emotional intelligence (EI), and if this relationship is mediated by their communication skills. Business students $(N=273)$ completed the 16 item self-report Workplace Emotional Intelligence Profile - Short Version (WEIP-S; Jordan \& Lawrence, 2009) before forming teams. Students worked in teams for eight weeks to complete group work. Afterwards, peer ratings of student communication appropriateness and effectiveness were collected as was each student's self-report perceptions of the level of team social cohesion. The effect of management of others' emotions on team social cohesion was mediated by communication effectiveness. We discuss the implications of EI training and student team allocation as possible ways to improve student team cohesion.
\end{abstract}

135 words

Keywords: teamwork, emotional intelligence, communication, social cohesion 


\section{Emotional Intelligence, Communication Competence and Student Perceptions of Team Social Cohesion}

The ability to manage and function within a team is a key skill employers seek in business school graduates (Amato \& Amato, 2005; Chen, Donahue, \& Klimoski, 2004). Demand for teamwork in organizations has seen business schools incorporate team building exercises and group projects into the curriculum. Students working in teams are thought to learn leadership, problem solving, communication and negotiation skills that will transfer to a work context (Hansen, 2006). Nevertheless, students generally dislike teamwork (Druskat \& Kayes, 2000) and prefer to work alone (Barr, Dixon, \& Gassenheimer, 2005). One explanation for student distaste of teamwork is the experience of poor team processes regarding issues of logistics, workload sharing, team dynamics, and leadership (Feichtner \& Davis, 1984; Hansen, 2006). These poor team processes are often encapsulated by low levels of cohesiveness within the team (Deeter-Schmelz, Kennedy, \& Ramsey, 2002). Indeed, Baldwin, Bedell, and Johnson (1997) argue that one way to promote student satisfaction with group work, and increase performance, is to increase social cohesion in teams.

Several researchers show low team social cohesion is a problem for students and has subsequent negative consequences for their performance (Harrion, Price, Gavin, \& Florey, 2002; Slavin, 1992). Cohesion is reflected in the tendency of the group to stick together and remain united when pursuing its goals and objectives (Carron, 1982). Teams with low social cohesion are less inclined to spend time together and more likely to experience greater relationship conflict which diverts attention from the task at hand (Jehn \& Mannix, 2001). Most empirical studies have focused on the cohesion-performance relationship, with few researchers exploring possible antecedents to student cohesion in teams. Harrison et al. (2002) showed greater team diversity is negatively related to team social cohesion, and Bacon, 
Stewart, and Silver (1999) found increasing team size was related to lower levels of team cohesion.

Our aim is to examine whether a student's level of emotional intelligence (EI) is related to their perceptions of team cohesion. Growing research focuses on the role of emotions, and specifically EI, on team experiences and functioning (e.g., conflict; decisionmaking) (Druskat \& Wolff, 2001; Elfenbein, Polzer, \& Ambady, 2007). EI has been defined as the ability to be aware of, and manage, the emotions of the self and others (Jordan \& Lawrence, 2009; Mayer \& Salovey, 1997), abilities shown to be important when working with others during team activities (Jordan \& Troth, 2004). There has been some preliminary empirical evidence linking higher levels of EI with greater social cohesion in student teams (Abraham, 1999; Rapisarda, 2002). One explanation for the link between EI and social cohesion is the greater communication skills of individuals with higher levels of EI (George, 2000). In this article, we extend research into EI and student teams by testing a mediation model of EI, communication effectiveness and appropriateness, and perceptions of team social cohesion. Establishing a link between university students' EI and their perceptions of team social cohesion, and understanding the mediating role of communication skills, will enable teachers to make decisions about student group formation and develop training options to improve student group experiences.

\section{Emotional Intelligence and Social Cohesion}

EI was initially described as the ability to be aware of and manage emotions to promote emotional and intellectual growth (Mayer \& Salovey, 1997). In examining EI in teams, Jordan and Lawrence (2009) built on the widely accepted Mayer and Salovey (1997) model of EI to show that team members need two primary EI abilities to deal with emotions in team contexts: (i) emotional awareness and (ii) emotional management. Both theoretical 
frameworks (Mayer \& Salovey, 1997) and empirical research (Jordan \& Lawrence, 2009; Jordan \& Troth, 2004) distinguish between abilities related to self (own emotions) and abilities related to others (others' emotions).

This results in four major constructs that contribute to team members EI: Awareness of Own Emotions, the ability to discuss and disclose the emotions one experiences (Pennebaker \& Francis, 1996); Awareness of Others' Emotions, the ability to recognize others' emotional displays and detect false emotional expressions (Mayer \& Salovey, 1997); Managing Own Emotions, the ability to connect or disconnect from an emotion depending on its usefulness in a situation (Mayer \& Salovey, 1997); and, Managing Others' Emotions, which enable a team member to encourage more positive and productive emotions from their team (Mayer \& Salovey, 1997). We argue these individual abilities contribute to enhanced team processes (Druskat \& Wolff, 2001; Elfenbein et al., 2007) that influence the quality of relationships in teams (Jordan \& Troth, 2004) and thus, student perceptions of team social cohesion.

We propose students with a greater ability to be aware of and manage their own emotions, and the emotions of their team-mates in a team setting, will be more likely to experience greater team cohesion. Indeed, Rapisarda (2002) found the EI competencies of influence, empathy and achievement orientation in 18 teams in an Executive MBA program were positively related to student and faculty ratings of team cohesiveness. On this basis we propose the following hypothesis:

H1: A student team member's EI will be positively related to their perceptions of team social cohesiveness.

\section{Communication Competence}


Swezey and Salas's (1992) conceptualization of team process principles included team communication as one of seven primary process categories that delineates effective from ineffective teams. Rather than communication of the team as a whole, we are interested in how an individual's EI influences their individual-level communication behaviors within a team. Zander (1994) asserts that open and easy communication within teams is critical for goal accomplishment and completion of regular, daily team activities.

Communication competence incorporates two fundamental outcome properties effectiveness and appropriateness (Spitzberg \& Cupach, 1984). Effective communication accomplishes the goals, objectives, or intended functions of the team member, whereas appropriate communication avoids the violation of the situational or relational rules governing the communicative context (Spitzberg \& Cupach, 1984). The implicit assumption is that competent communication behaviors are both appropriate and effective.

To achieve individual communication competence, we argue that student team members need to be aware of, and to manage, the emotions of team members. A combination of emotional awareness and emotional management is more likely to ensure the relational rules governing communication are not violated within the team and that effective communication can occur (Canary \& Cupach, 1988; Canary \& Spitzberg, 1987). Research suggests team members more capable of recognizing and managing their own and others' emotions during interactions are more likely to engage in better information exchange and decision making (e.g., Jordan \& Troth, 2004), resolve task conflict, and display less relationship conflict than individuals with lower levels of EI (Yang \& Mossholder, 2004). Thus, we propose:

H2: A student team member's EI will be positively related to their communication effectiveness and communication appropriateness. 
Lieberman, Yalom, and Miles (1973) conceptualize team social cohesion as team members' feelings of belongingness or attraction to the group (see also Carron, 1982). Barrick, Stewart, Neubert, and Mount (1998) found significant links between communication competence in teams and indices of social cohesion. In order for social cohesiveness to emerge, quality relationships need to be established within the team (Mitchell, 1986). Effective and socially appropriate communication enhances the quality of relationships (Smith, Smith, Olian, Sims, O’Bannon, \& Scully, 1994). We propose that:

H3: A student team member's communication effectiveness and appropriateness will be positively related to their perceptions of team social cohesiveness.

\section{Emotional Intelligence, Communication and Social Cohesion}

As noted above, there is evidence of positive links between EI and team social cohesion (Abraham, 1999; Rapisarda, 2002), between team member EI and communication efficiency with fellow team members (Jordan \& Troth, 2004), and between individual communication competence and perceptions of team social cohesion (Barrick et al., 1998). We argue that the main mechanism by which EI influences individual's perceptions of team social cohesion is through the mediating influence of individual communication competence. To date this link has not been theoretically or empirically explored.

We argue this mediated effect occurs because students higher in EI will engage in more positive interpersonal behaviors (Elfenbein et al., 2007), including competent communication. They will also have greater ability to influence the communication behaviors of other team members. Reciprocal communication within the group, initiated by students higher in EI, will promote their feelings of attraction and belongingness to the team (Mitchell, 1986). Thus, we propose the following: 
H4: A student team member's ratings of their communication effectiveness and appropriateness will mediate the relationship between EI and perceptions of team social cohesiveness.

\section{Method}

\section{Participants}

Our final sample comprised a total of 273 business university students belonging to 75 teams (with 3 or more members) who voluntarily completed surveys at time 1 and time 2 . This final sample represented an overall response rate of $48 \%$. Survey 1 was completed by $376(66 \%)$ participants and Survey 2 was completed by 540 (95\%). They belonged to teams where the average team size was 5 members $(M=5.36, S D=2.10)$, ranging from 3 - 8 members. Of these, $122(45 \%)$ were male and 151 (55\%) were female; 142 (52\%) were born in Australia and 131 $(48 \%)$ were born overseas. Mean age was 22 years $(S D=4.30)$, ranging from 17 to 45 years.

\section{Procedure}

Respondents worked in a single team to complete group work over a semester. Respondents formed self-selected teams with no prior history of working together and met every week in class to undertake group work for approximately eight weeks. An initial survey was administered in class during the second week of semester to assess students' perceived level of EI abilities within a team context. A second survey containing the mediator and dependent variables was administered during tutorials eight weeks later. Team members were asked to reflect on the level of social cohesion that existed within their team during the previous two months and asked to rate the communication effectiveness and appropriateness behaviors of each of their fellow team members during the group work. 


\section{Measures}

Team social cohesion. Team social cohesion ( 7 items) was adapted from Stokes (1983) and O'Reilly, Caldwell, and Barnett (1989). Respondents were asked to rate their agreement about how well their team functioned as a group in terms of these items $(1=$ strongly disagree to $5=$ strongly agree). Sample items include, "The members of this team got along well with each other" and "Team members consistently helped each other with the assessment task". All items were averaged into a single score.

Emotional intelligence. Participants completed the self-report Workplace Emotional Intelligence Profile - Short Version (WEIP-S; Jordan \& Lawrence, 2009). The WEIP-S assesses a team member's emotional awareness and emotional management within a team context and has an own and other focus. The scale captures four dimensions (4 items each): Awareness of Own Emotions (e.g., "I am aware of my own feelings when working in a team"), Management of Own Emotions (e.g., When I am frustrated with fellow team members, I can overcome my frustration”), Awareness of Others' Emotions (e.g., "I am able to describe accurately the way others in the team are feeling"), and Management of Others' Emotions (e.g., "I am able to cheer team members up when they are feeling down") . Respondents indicated their level of agreement with each item using a 7-point format $(1=$ strongly disagree to $7=$ strongly agree). Items for each subscale were averaged to provide a score for each respondent.

Communication. Canary and Spitzberg's (1987) Communication Effectiveness (7item) and Appropriateness (4-item) scales asked team members to rate each of their fellow team members' communication (peer rating) over the previous 8 weeks. A 5-point response format $(1=$ strongly disagree to $5=$ strongly agree $)$ was employed. Items were modified to assess the communication of specific team members. Sample items included, "He/she achieved what he/she apparently wanted to achieve in our conversations" (Communication 
Effectiveness), and "His/her conversations were very suitable to the situation" (Communication Appropriateness).

Control variables. Gender and national origin (Australian; not born in Australia) were included as control variables. Information on the team size was also collected.

\section{Results}

\section{Interrater Reliability Checks and Descriptives}

Within-group inter-rater reliabilities were conducted because the ratings of independent observers are often idiosyncratic. This is important to establish agreement across peer raters for communication effectiveness and appropriateness for each group member (James, Demaree, \& Wolf, 1993). Overall scale reliability for communication appropriateness and effectiveness using all available peer ratings for the 75 groups $(n=1775$ peer ratings for 380 ratees) was calculated to ascertain the consistency of team members' ratings. Overall Cronbach's alpha reliability for communication effectiveness was .87 and communication appropriateness was 77. Within-group interrater reliability $\left(r_{w g}\right)$ tests computed for each team member revealed a mean $r_{w g}$ for communication effectiveness of .94 with a median $r_{w g}$ of .96 , and a mean $r_{w g}$ for communication appropriateness of .80 with a median $r_{w g}$ of .92 . Given these satisfactory values, each group member received an averaged aggregated score across peers for every communication performance item. The mean of these aggregated peer-rated scale items were then used to operationalize the two individual-level communication competence variables for mediation.

Table 1 presents means, standard deviations, Cronbach's alpha reliabilities, and correlations for all variables and controls. As expected (Pelled, Eisenhardt, \& Xin, 1999), the demographic variables of gender and nationality influenced individuals' perceptions of team social cohesion and their ratings of team members' communication competence. No 
significant correlations emerged between team size and perceptions of team cohesion or communication effectiveness and appropriateness. Thus, team size was not controlled for in subsequent analyses.

Insert Table 1 about here

\section{Mediational Analyses}

We tested our mediation hypotheses (Hypotheses 1-4) using Preacher and Hayes’ (2004) SPSS macros to calculate bootstrapped multiple mediation effects. The indirect effects method of conducting mediation analyses is considered superior to the combined approach of using the Baron and Kenny (1986) method and Sobel tests (Preacher \& Hayes, 2004; Preacher, Rucker, \& Hayes, 2007). Table 1 shows while management of others' emotions positively correlated with ratings of student communication effectiveness and appropriateness, and perceptions of team social cohesion, the other EI subscales did not correlate. Thus, we only assessed whether the effect of management of others emotions on perceptions of team social cohesion was mediated by (a) communication effectiveness and (b) communication appropriateness. Both variables were entered as mediators in the same indirect effects analysis. Student gender and country of origin were also statistically controlled. Mediation is significant if the $95 \%$ confidence intervals for the indirect effect (IE) do not include zero.

See Figure 1 for a schematic overview of the tested meditational models and the obtained B weights. Results based on 2, 000 bootstrapped samples for mediation by communication effectiveness revealed that the confidence interval $(\mathrm{CI})$ for the indirect effect did not include zero (IE lower $95 \% \mathrm{CI}=0.01$, upper $95 \% \mathrm{CI}=0.06$ ), and both the relationship between management of others emotions and communication effectiveness and that between communication effectiveness and team social cohesion were significant $(t=3.04$, 
$S E=.05, p<.05$, and $t=3.12, S E=.06, p<.05$, respectively). This provides evidence that communication effectiveness mediated the association between management of others emotions and perceptions of team social cohesion ( $\mathrm{p}<.05$, two tailed).

However, these mediation analyses indicated that zero was included in the $95 \%$ confidence interval when analyzing mediation by communication appropriateness (IE lower $95 \% \mathrm{CI}=-.01$, up $95 \% \mathrm{CI}=.03$ ). Furthermore, while the effect from management of others emotions on the mediator was confirmed $(t=2.72, S E=.06, p<.05)$, communication appropriateness did not relate to team social cohesion $(t=0.21, S E=.05, p=.83)$. This suggests that communication appropriateness does not mediate the relationship between management of others emotions and team social cohesion.

\section{Discussion}

Partial support was found for our hypotheses regarding the impact of university students' EI on their subsequent perceptions of team social cohesion via the intermediary mechanism of individual communication effectiveness (Hypothesis 4). More specifically, students' ability to manage others' emotions emerged as the salient predictor in terms of their peer-rated communication competence (Hypotheses 2) and their own team cohesion perceptions (Hypothesis 1). The positive relationships found between student EI and their communication effectiveness and appropriateness supports Jordan and Troth's (2004) findings of a positive EI and collaborative conflict resolution relationship. Our findings also indicate a positive relationship between communication effectiveness and social cohesion in teams (Hypothesis 3) which lends support to Barrick et al. (1998) who found a positive link between communication and cohesion in work teams. It appears a similar relationship holds for student teams. 
Differentiating the four EI abilities highlighted the salient ability of managing others emotions in both student communication competence and their experiences of team cohesion. We found a student's ability to deal effectively with others emotions in a team setting is viewed favorably by team mates in terms of communication competence, and in terms of the student's own perceptions of team social cohesion (Mayer \& Salovey, 1997). Unexpectedly, a student team member's ability to recognize their own and others' emotions did not impact on their communication competence as perceived by their team-mates, nor promote their feelings of belongingness. Indeed, there is some empirical research to suggest emotional awareness might be an impediment to functioning within teams (Jordan \& Troth, 2004) as constantly focusing on how oneself and others feel detracts attention from task performance (Foo, Elfenbein, Tan, \& Aik, 2004).

Our finding that only others' emotional management promotes social cohesion via communication effectiveness also needs to be considered in terms of our collection of peerratings of student communication. Peers were asked to rate individual team members on their ability to achieve communication goals. We suggest that high ratings of communication effectiveness requires the student, in addition to being collaborative (e.g., listening to others point of view, suggesting collective solutions), to predominantly engage in the persuasive influence of other members about team goals. A student's ability to communicate persuasively is likely to be salient and observable to peers when evaluating the student, particularly if the communication has been directed at them. We argue that the ability to manage others emotions is a major determinant of the degree to which a student can linguistically persuade or influence (both emotionally and through cognitive arguments) a peer. This does not mean other EI abilities do not influence communication effectiveness, rather the persuasive element of communication effectiveness is weighed more heavily when determining a peer rating about communication effectiveness and hence, the significant 
relationship between management of others emotions and communication effectiveness. Furthermore, the reported influence of EI on individual behaviors has been commonly associated with small effect sizes (Jordan \& Ashkanasy, 2006; Roberts, Zeidner, \& Matthews, 2001) and it may be the case that data from a larger sample would have provided the statistical power to observe the impact of the other EI abilities on individual perceptions and peer-rated behaviors.

\section{Implications for Theory and Practice}

This study increases understanding about how EI is resourced and utilized within student teams and, via the promotion of competent communication processes, increases student perceptions of social cohesion. Researchers suggest team social cohesion helps individuals gain a sense of identification and maximize their potential for team performance (Deeter-Schmelz et al., 2002). The findings also contribute to existing work that explores individual and contextual factors that influence perceptions of team social cohesiveness (Mullen \& Copper, 1994) and literature that suggests the EI abilities of team members are an important antecedent of team processes (Ashkanasy \& Dasborough, 2003; Bell, 2007).

We noted in our introduction that university students generally dislike group work. The mediating effect found for communication competence has practical implications. The level of student's EI may be a useful factor to consider when determining student team allocation configurations. While there is debate over whether EI can be trained (Lindebaum, 2009), there is strong evidence communication skills can be trained and communication norms can be learned. Communication skills training early in a university degree could result in students better able to engage in teamwork and have a more positive experience. This suggests the development of communication and emotional skills should become an important 
part of team building to ensure a maximum opportunity for optimizing performance (Jordan \& Ashkanasy, 2006).

\section{Limitations and Future Directions}

One limitation is our use of an EI self-report measure. Although the WEIP-S has been validated (Jordan \& Lawrence, 2009) and used in previously published research (Kellett, Humphrey, \& Sleeth, 2006), there is debate regarding the validity of self-report measures of EI and the need to control for both personality and cognitive intelligence (Roberts et al., 2001). We believe it would be worthwhile to examine in university course contexts the impact of EI on communication, and perceptions of team processes, using both self-report and ability-based EI measures, and to control for personality and cognitive intelligence.

Data dependence effects are another possible limitation (Henderson, Wayne, Shore, Bommer, \& Tetrick, 2008). Our individual student data is nested within student teams. This means that some of the variance explained in individual perceptions of team social cohesion may be due to differences between student teams. Unfortunately, current multi-level modeling statistical techniques cannot analyse bottom-up cross-level theoretical models to statistically separate the variance attributable to individuals and teams. Given that we were able to establish a significant indirect link between individual-level EI, communication effectiveness and perceptions of social cohesion within student teams, future research should also try to establish whether such a link is theoretically and empirically plausible at the team level (team EI, team communication effectiveness, team social cohesion), and whether this team-level mediated mechanism also impacts on student team performance outcomes. O’Boyle, Humphrey, Pollack, Hawver, and Story's (2011) meta-analysis provides convincing evidence that EI (ability-based or self-report measures) predicts work performance. It is conceivable this will also translate to performance in student teams. 


\section{References}

Abraham, R. (1999). Emotional intelligence in organizations: A conceptualization. Genetic, Social, and General Psychology Monographs, 125, 209 - 224.

Amato, C. H., \& Amato, L. H. (2005). Enhancing student team effectiveness: Application of Myers-Briggs personality assessment in business courses. Journal of Marketing Education, 27, 41-51.

Ashkanasy, N. M., \& Dasborough, M. T. (2003). Emotional awareness and emotional intelligence in leadership teaching. Journal of Education for Business, 79, 18-23.

Bacon, D. R., Stewart, K. A., \& Silver, W. S. (1999). Lessons from the best and worst student team experiences: How a teacher can make a difference. Journal of Management Education, 23, 467-488.

Baldwin, T. T., Bedell, M. D., \& Johnson J. L. (1997). The social fabric of ateam-based M.B.A. program: Network effects on student satisfaction and performance. The Academy of Management Journal, 40, 1369-1397.

Baron, R. M., \& Kenny, D. A. (1986). The moderator-mediator variable distinction in social psychological research: Conceptual, strategic and statistical considerations. Journal of Personality and Social Psychology, 51, 1173-1182.

Barr, T. F., Dixon, A. L., \& Gassenheimer, J. B. (2005). Exploring the "Lone Wolf" phenomenon in student teams. Journal of Marketing Education, 27, 81-90.

Barrick, M. R., Stewart, G. L., Neubert, M. J., \& Mount. M. K. (1998).Relating member ability and personality to work-team processes and team effectiveness. Journal of Applied Psychology, 83, 377-391.

Bell, S. T. (2007). Deep-level composition variables as predictors of team performance: A meta-analysis. Journal of Applied Psychology, 92, 595-615. 
Canary, D. J., \& Cupach, W. R. (1988). Relational and episodic characteristics associated with conflict tactics. Journal of Social and Personal Relationships, 5, 305-325.

Canary, D. J., \& Spitzberg, B. H. (1987). Appropriateness and effectiveness perceptions of conflict strategies. Human Communication Research, 14, 93-118.

Carron, A. V. (1982). Cohesiveness in sport groups: Interpretations and considerations. Journal of Sport Psychology, 4, 123-138.

Chen, G., Donahue, L. M., \& Klimoski, R. J. (2004). Training undergraduates to work in organizational teams. Academy of Management Learning and Education, 3, 27-40.

Deeter-Schmelz, D. R., Kennedy, K, R., \& Ramsey, R. P. (2002). Enriching our understanding of student team effectiveness. Journal of Marketing Education, 24, 114-124.

Druskat, V. U., \& Kayes, D. C. (2000). Learning versus performance in short-term teams. Small Group Research, 31, 328-353.

Druskat, V. U., \& Wolff, S. B. (2001). Building the emotional intelligence of groups. Harvard Business Review, 79, 80-91.

Elfenbein, H. A., Polzer, J. T., \& Ambady, N. (2007). Can teams have emotional skills? The case of recognizing others' emotions. In C. E. J. Härtel, N. M. Ashkanasy \& W. J. Zerbe (Eds.), Research on emotion in organizations, Volume 3: The functional role of emotion in organizations (pp. 87-120). Oxford, UK: Elsevier/JAI Press.

Feichtner, S. B. \& Davis E. A. (1984). Why some groups fail: A survey of students' experiences with learning groups. Journal of Management Education, 9, 58-73.

Foo, M. D., Elfenbein, H. A., Tan, H. H., \& Aik, V. C. (2004). Emotional intelligence and negotiation: The tension between creating and claiming value. International Journal of Conflict Management, 15, 411-29 
George, E. (2000). Emotions and leadership: The role of emotional intelligence. Human Relations, 53, 1027-1055.

Hansen, R. S. (2006). Benefits and problems with student teams: Suggestions for improving team projects. Journal of Education for Business, 82, 11-19.

Harrison, D. A., Price, K. H., Gavin, J. H., \& Florey, A. T. (2002). Time, teams and task performance: Changing effects of surface- and deep-level diversity on group functioning. Academy of Management Journal, 45, 1029-1045.

Henderson, D. J., Wayne, S. J., Shore, L. M., Bommer, W. H., \& Tetrick, L. E. (2008). Leader-member exchange, differentiation, and psychological contract fulfillment: A multilevel examination. Journal of Applied Psychology, 93, 1208-1219.

James, L. R., Demaree, R. G., \& Wolf, G. (1993). An assessment of within-group interrater agreement. Journal of Applied Psychology, 78, 306-309.

Jehn, K., \& Mannix, E. A. (2001). The dynamic nature of conflict: A longitudinal study of intragroup conflict and group performance. Academy of Management Journal, 44, 238-251.

Jordan, P. J., \& Ashkanasy, N. M. (2006). Emotional intelligence, emotional self-awareness, and team effectiveness. In V. U. Druskat, F. Sala. \& G. J. Mount (Eds.), Linking emotional intelligence and performance at work (pp. 145-164). San Francisco: JosseyBass.

Jordan, P. J., \& Lawrence, S.A. (2009). Emotional intelligence in teams: Development and initial validation of the short version of the workgroup emotional intelligence profile (WEIP-S). Journal of Management \& Organization, 15, 452-465.

Jordan, P. J., \& Troth, A. C. (2004). Managing emotions during team problem solving: Emotional intelligence and conflict resolution. Human Performance, 17, 195-218. 
Kellett, J. B., Humphrey, R. H., \& Sleeth, R. G. (2006). Empathy and the emergence of task and relations leaders. The Leadership Quarterly, 17, 146-162.

Lieberman, M. A., Yalom, I. D., \& Miles, M. B. (1973). Encounter groups: First facts. New York, NY: Basic Books.

Lindebaum, D. (2009). Rhetoric or remedy? A critique on developing emotional intelligence. Academy of Management Learning and Education, 8, 225-237.

Mayer, J., \& Salovey, P. (1997). What is emotional intelligence? In P. Salovey, \& D. Sluyter (Eds.), Emotional development and emotional intelligence: Implications for educators (pp. 3-31). New York: Basic Books.

Mitchell, R. (1986). Team-building by disclosure of internal frames of reference. Journal of Applied Behavioral Science, 22, 15-28.

Mullen, B., \& Copper, C. (1994). The relation between group cohesiveness and performance: An integration. Psychological Bulletin, 115, 210-217.

O'Reilly, C. A., Caldwell, D. F., \& Barnett, W. P. (1989). Work group demography, social integration, and turnover. Administrative Science Quarterly, 34, 21-37

O’Boyle, E. H., Humphrey, R. H., Pollack, J. M., Hawver, T. H., \& Story, P. A. (2011). The relation between emotional intelligence and job performance: A meta-analysis. Journal of Organizational Behavior, 32, 788-818.

Pennebaker, J. W., \& Francis, M. E. (1996). Cognitive, emotional, and language processes in disclosure. Cognition and Emotion, 10, 601-626.

Pelled, L. H., Eisenhardt, K. M., \& Xin, K. R. (1999). Exploring the black box: an analysis of work group diversity, conflict, and performance. Administrative Science Quarterly, 44, $1-28$. 
Preacher, K. J., \& Hayes, A. F. (2004). SPSS and SAS procedures for estimating indirect effects in simple mediation models. Behavior Research Methods Instruments \& Computers, 36, 717-731.

Preacher, K. J., Rucker, D. D., \& Hayes, A. F. (2007). Addressing moderated mediation hypotheses: Theory, methods and prescriptions. Multivariate Behavioral Research, 42, $185-227$.

Rapisarda, B. A. (2002). The impact of emotional intelligence on work team cohesiveness and performance. The International Journal of Organizational Analysis, 10, 363 - 379.

Roberts, R. D., Zeidner, M., \& Matthews, G. (2001). Does emotional intelligence meet traditional standards for an intelligence? Some new data and conclusions. Emotion, 1, $196-231$

Slavin, R. E. (1992). When and why does cooperative learning increase achievement? Theoretical and empirical perspectives. In R. Hertz-Lazarowitz \& N. Miller (Eds.), Interaction in cooperative groups: The theoretical anatomy of group learning (pp. 145-173). New York: Cambridge University Press.

Smith, K. G., Smith, K. A., Olian, J. D., Sims, H. P., O'Bannon, D. P., \& Scully, J. A. (1994). Top management team demography and process: The role of social integration and communication. Administrative Science Quarterly, 39, 412-438.

Stokes, J. P. (1983). Toward an understanding of cohesion in personal change groups. International Journal of Group Psychotherapy, 33, 449-67.

Spitzberg, B. H., \& Cupach, W. R. (1984). Interpersonal communication competence. Beverly Hills, CA: Sage

Swezey, R. W., \& Salas, E. (1992). Guidelines for use in team-training development. In R. W. Swezey \& E. Salas (Eds.), Teams: Their training and performance (pp. 219-245). Norwood, NJ: ABLEX. 
Yang, J. X., \& Mossholder, K. W. (2004). Decoupling task and relationship conflict: The role of intra-group emotional processing. Journal of Organizational Behavior, 25, 589-605.

Zander, A. (1994). Making groups effective (2 ${ }^{\text {nd }}$ ed.). San Francisco, CA: Jossey-Bass. 

Table 1

Means, standard deviations, reliabilities and correlations among study variables.

\begin{tabular}{|c|c|c|c|c|c|c|c|c|c|c|}
\hline Variables & 1 & 2 & 3 & 4 & 5 & 6 & 7 & 8 & 9 & 10 \\
\hline 1. Gender & --- & & & & & & & & & \\
\hline 2. National Origin & -.08 & --- & & & & & & & & \\
\hline 3. Team Size & .02 & -.04 & --- & & & & & & & \\
\hline 4. Own Aware & $.16^{* *}$ & .05 & -.01 & $(.78)$ & & & & & & \\
\hline 5. Own Manage & -.02 & -.05 & -.04 & $.27^{* *}$ & $(.68)$ & & & & & \\
\hline 6. Other Aware & .05 & $-.13^{*}$ & -.04 & $.49^{* *}$ & $.25^{* *}$ & $(.74)$ & & & & \\
\hline 7. Other Manage & .09 & $-.13^{*}$ & -.08 & $.50^{* *}$ & $.26^{* *}$ & $.39^{* *}$ & $(.76)$ & & & \\
\hline 8. Communication Effectiveness & $.17^{* *}$ & $-.39^{* *}$ & -.04 & .02 & .07 & .05 & $.23^{* *}$ & $(.87)$ & & \\
\hline 9. Communication Appropriateness & .10 & $-.35^{* *}$ & .08 & .03 & .10 & .04 & $.20^{* *}$ & $.75^{* *}$ & $(.77)$ & \\
\hline 10. Team Social Cohesion & $.13^{*}$ & $-.14^{*}$ & -.05 & -.02 & .09 & -.02 & $.13^{*}$ & $.33^{* *}$ & $.25^{* *}$ & $(.85)$ \\
\hline Mean & 1.56 & 1.48 & 5.36 & 4.28 & 5.45 & 4.73 & 4.71 & 3.93 & 3.89 & 4.12 \\
\hline SD & 0.50 & 0.50 & 2.10 & 1.11 & 0.82 & 0.90 & 0.88 & 0.41 & 0.44 & 0.61 \\
\hline
\end{tabular}

Note. Dichotomous variable codes for gender: male $=1$; female $=2$; National origin: $0=$ Australasian born; $1=$ non-Australasian born; Cronbach's alpha reliabilities appear in parentheses along diagonal.

${ }^{*} p<.05,{ }^{* *} p<.01$. 


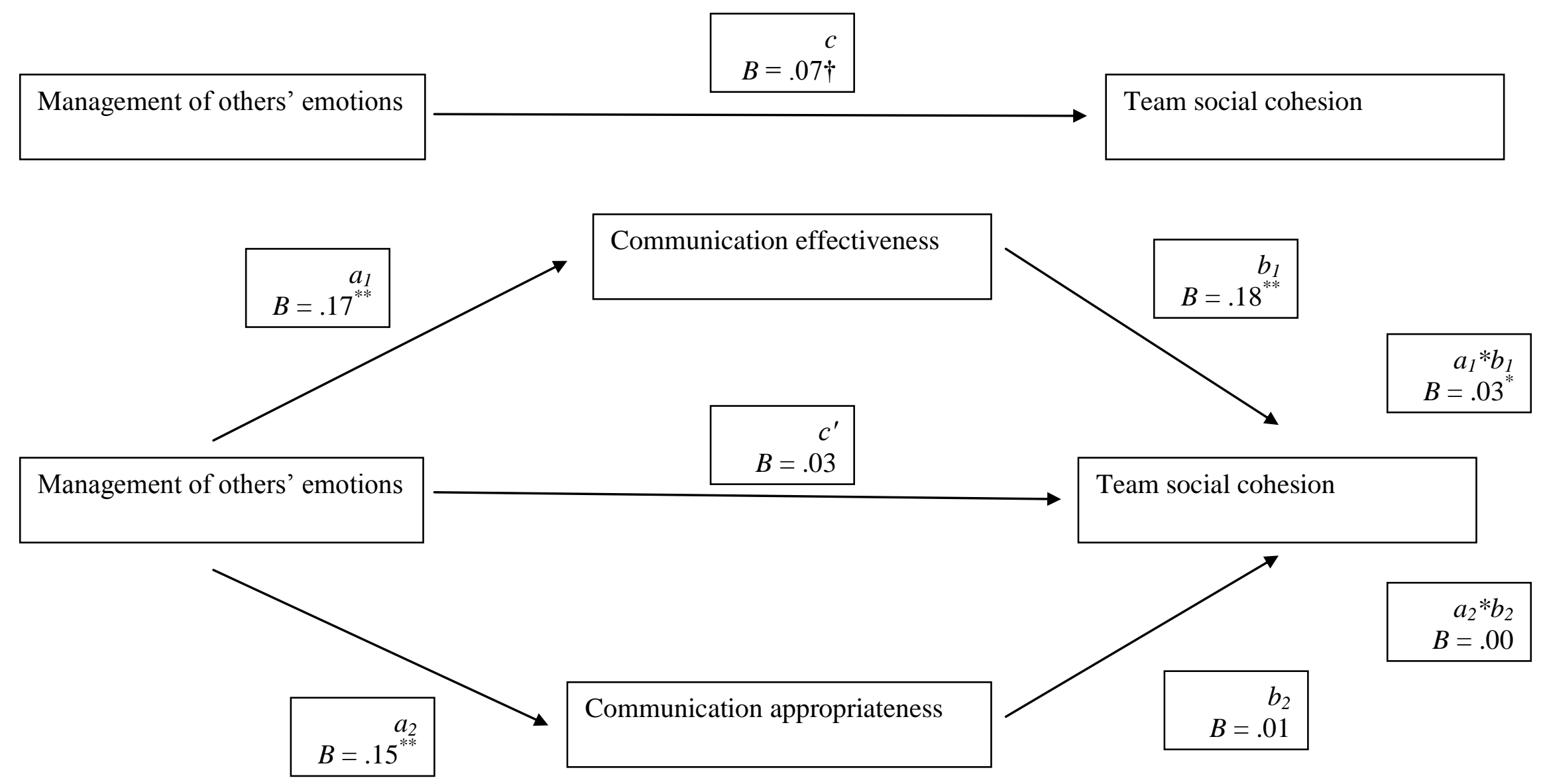

$\operatorname{Adj} R^{2}=.10, F(5,267)=7.07, p<.01$.

Figure 1. Model of the relationship between management of others emotions and perceptions of team social cohesion mediated by communication effectiveness and appropriateness. $\dagger p=.07,{ }_{p}^{*}<.05,{ }^{* *} p<.01$.

$c^{\prime}=c$, controlling for mediators; $a_{1} * b_{1}, a_{2} * b_{2}=$ indirect effects, respectively, via communication effectiveness and appropriateness. 